\title{
Article
}

\section{Correlation between genotype and phenotype in adult primary open angle Glaucoma and mutations in myoc gene}

\author{
Rabia Mushtaq ${ }^{1, *}$, Rasheeda Bashir ${ }^{1}$, Haniya Kalsoom ${ }^{2}$, Shagufta Naz ${ }^{1}$, Sadaf Naz $^{1}$ and Maria Hasnain ${ }^{1}$ \\ 1 Department of Biotechnology, Lahore College for Women University, Lahore, Pakistan. \\ 2 Department of Chemistry, Lahore College for Women University, Lahore, Pakistan. \\ * Correspondence: rbutt7011@gmail.com
}

Received: 25 September 2019; Accepted: 1 December 2019; Published: 15 December 2019.

\begin{abstract}
Glaucoma is a second leading cause of blindness worldwide and stands on fourth position among the cause of blindness. Two main types of Glaucoma, primary congenital Glaucoma (PCG) and primary open angle Glaucoma (POAG). Primary open angle Glaucoma is further classified in to primary juvenile open angle Glaucoma JOAG (age of onset 3-35 years) and adult onset open angle Glaucoma (after the age of 35 years). Myocilin (MYOC) gene plays a major role in the development of adult primary open angle Glaucoma (POAG). Mutations in Myocilin (MYOC) gene are well documented to cause Adult Primary Open Angle Glaucoma (POAG). Currently, very few data is available on the contribution of Myocilin (MYOC) gene in POAG in Pakistani population. In present study, fifty seven sporadic cases of autosomal recessive samples of Primary Open Angle Glaucoma (POAG) were collected from different hospitals of Lahore, Pakistan. Sequencing was performed to check the contribution of (MYOC) gene and to identify the common mutations present in Pakistani population. Sequencing results revealed previously reported one heterozygous synonymous single nucleotide polymorphism SNP and a variant in intronic exonic boundary of exon 2. Findings of this study revealed that contribution of (MYOC) gene is high. Therefore, there is need to enroll more patients and families to identify the pathogenic mutations in (MYOC) gene to report actual frequency of this gene and its mutations in our population. Mutations identified in this gene may be helpful at clinical level to diagnose the disease at early stages.
\end{abstract}

Keywords: Myocilin (MYOC), primary open angle Glaucoma (POAG), primary congenital Glaucoma (PCG).

\section{Introduction}

G laucoma represents a heterogeneous group of neuro-degenerative disorders of the eye. Glaucoma is characterized by progressive loss of retinal ganglion cells resulting in a loss of peripheral vision and a characteristic excavated atrophy of the optic nerve, resulting in blindness if untreated. Commonly associated features of Glaucoma are prolonged painless progression, increased intraocular pressure (IOP), death of retinal ganglion cells (RGC"s), loss of the visual field, optic nerve damage, cupping of optic disc and structural defect in the trabecular meshwork [1,2]. Glaucoma affects 67 million people worldwide [3]. According to the WHO survey 2002, second leading cause of blindness is Glaucoma globally. It accounts for $12.3 \%$ of global blindness [4]. Glaucoma is influenced by multiple genetic and environmental factors [5]. According to National Health Survey Prevalence of Glaucoma in Pakistan is 2.7\%. Glaucoma was found forth main cause of blindness in Pakistan [6]. Another study revealed that Glaucoma is accountable for 3.9\% of blindness in Pakistan [7].

Glaucoma can be classified on the basis of etiology primary and secondary, age of onset congenital (onset up to 3 years of age), juvenile (onset after 3-35 years) and adult (onset after the age of 35 years) and anatomy of anterior chamber angle that is open angle and angle closure [8]. There are number of genes involved in POAG pathology myocilin (MYOC), Cytochrome P4501B1 (CYP1B1), optineurin (OPTN) and WDR 36 genes [9]. Mutation in MYOC gene has major role in Adult Primary Open Angle Glaucoma POAG rather than other CYP1B1, OPTN and WDR36 genes. MYOC gene consists of 3 exons that encode for an mRNA of about $2.5 \mathrm{~kb}$ and $57-\mathrm{kDa}$ glycoprotein of 504 amino acids. About $90 \%$ of these mutations have been seen to cluster at exon III of the MYOC gene [10,11]. 
The present study aims to explore the genetic basis of autosomal recessive Glaucoma in Pakistan. Pakistan is a country where ratio of cousin marriages is $72.2 \%$ in which $87 \%$ are first cousins [12]. It increases the chance of inheritance of recessive disorders like Primary Open Angle Glaucoma POAG. There is only Thr 377 Arg mutation reported contribution of responsible genes MYOC of Glaucoma in Pakistan [13]. MYOC is common gene in Primary Open Angle Glaucoma POAG and also has contribution in the onset of PCG while CYP1B1 and LTBP2 has important role in PCG and act as Modifiers in POAG [14]. So, this study will contribute in the basic understanding of molecular basis of recessive Glaucoma in Pakistan and Contribution of MYOC genes in Pakistani population.

\section{Materials and methodology}

\subsection{Extraction of genomic DNA from blood}

$5 \mathrm{ml}$ of blood sample was collected from the recruited patients after completing the clinical assessment. Whole genomic DNA was extracted from blood samples by using a non-organic method (Grimberg et al., 1989). DNA was loaded on $0.8 \%$ agarose gel for qualitative and quantitative DNA analysis.

\section{Linkage analysis}

DNA from the affected individuals were checked for linkage to known GLC1 locus by homozygosity mapping. In homozygosity mapping search of single allele of adjacent marker which are tightly linked to genes are identified which cause recessively inherited disorder. After genotyping allele were called by poly acrylamide gel electrophoresis or capillary electrophoresis. Linkage analysis is a classical method to find the location of diseased gene.

\section{PCR with microsatellite marker}

68 sporadic individuals samples affected with POAG were selected for linkage analysis. For initial screening two set of microsatellite markers primers flanking myocilline gene were used and to amplify upstream and downstream of MYOC gene two sets of microsatellite markers D1S2851 (Position 188.32 CM) and D1S2815 (position 188.85 CM) located upstream and downstream of MYOC gene reported in Marshfield map were used. Primers were labelled with M13 tail for genotyping.

L $\begin{array}{llllll}1 & 2 & 3 & 4 & 5 & 6\end{array}$

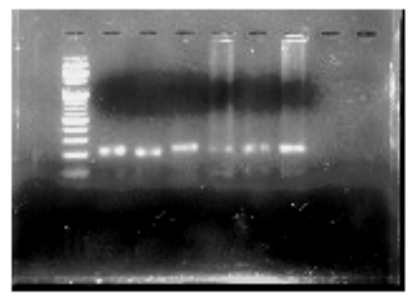

(a)
$987654321 \mathrm{~L}$

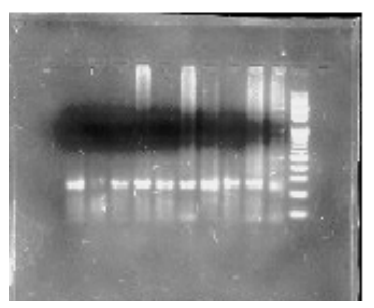

(b)
237

Figure 1. (a) PCR amplified products of marker D1S2815 resolved on $1.5 \%$ agarose gel (b) PCR amplified products of marker D1S2851 resolved on 1.5\% agarose gel

Table 1. Procedures of the experiments for the corrosive properties in crude oils

\begin{tabular}{|c|c|c|c|c|c|}
\hline Marker name & & Marker sequence & Tm & Product size & Hetrozygosity \\
\hline \multirow{3}{*}{ D1S2851 } & $\bar{F}$ & CACGACGTTGTAAAACGAC & $55.47 \mathrm{C}$ & \multirow{3}{*}{$169-199$ bps } & \multirow{3}{*}{0.83} \\
\hline & & ТСТTСССАССАСТGСС & & & \\
\hline & $\mathrm{R}$ & TTTATATTTGTATTCCTACTGCCCA & $54.46 \mathrm{C}$ & & \\
\hline \multirow{3}{*}{ D1S2815 } & $\mathrm{F}$ & CTGACATGGAATACCTCTATGATGC & $34.35 \mathrm{C}$ & \multirow{3}{*}{$210-237 \mathrm{bps}$} & \multirow{3}{*}{0.70} \\
\hline & & CACGACGTTGTAAAACGAC & & & \\
\hline & $\mathrm{R}$ & СТССАААТСТАGTCACACTGGAAG & $56.96 \mathrm{C}$ & & \\
\hline
\end{tabular}




\subsection{Genotyping}

Genotyping was done by $6 \%$ Poly Acrylamide Gel Electrophoresis (PAGE) Samples were prepared by denaturing the PCR product in thermocycler at 94 řC for five minutes mixed with formamide loading dye and loaded on gel. Ethidium bromide staining was used to visualize the DNA bands in Gel. Some samples were genotyped by using Capillary Electrophoresis method.

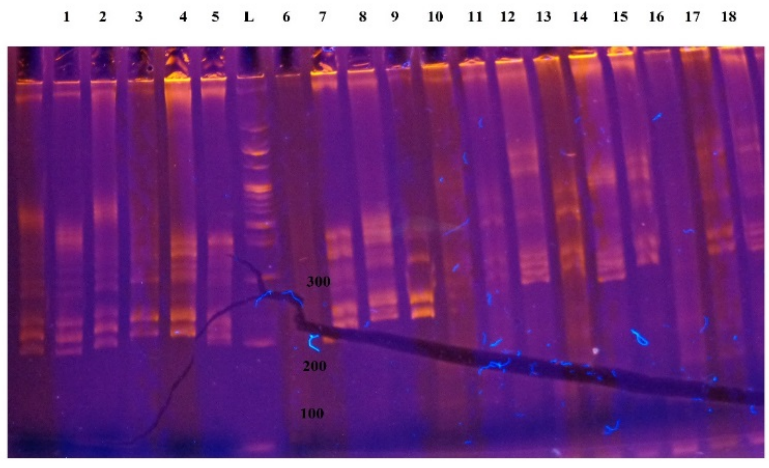

Figure 2. Some representative sporadic samples of POAG genotyped on 6\% Poly acrylamide gel.

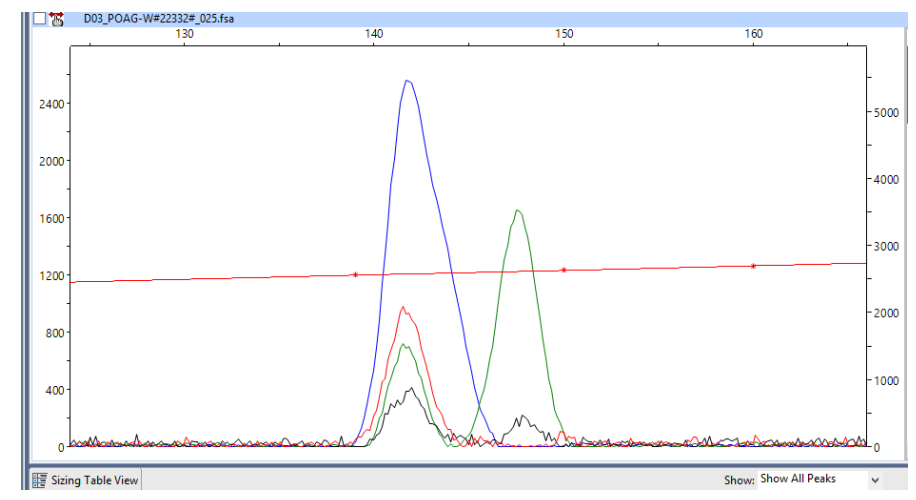

Figure 3. Some representative sporadic sample of POAG genotyped by capillary electrophoresis

\subsection{Capillary Electrophoresis}

The pooling of fluorescently labeled PCR products was performed. The intensity of emitted fluorescence is different for all dyes. Hence, the use of greater amount of PCR product was made in case of use of dye of lower intensity.4-5 $\mu l$ of HEX, $3 \mu l$ of FAM, labeled PCR product were used in single pooling. The dilution of pooled PCR products was made with water (1:5). The diluted sample of about $1 \mu l$ was combined with $12 \mu l$ of Hi- Di TM formamide (Applied Biosystems, Foster City, CA). The addition of internal size control LIZ 500 was made for the purpose of allele calling and sizing in every lane. The denaturation of samples was carried out at $96^{\circ} \mathrm{C}$ for 5 minutes and then the samples were placed on ice and later electrophoresis was carried out for them in ABI PRISM 310 or 3730 ABI genetic analyzer (Figure 17).

\subsection{PCR amplification of coding exon 2 and 3 of MYOC}

The coding exon 3 of MYOC gene of affected individuals was amplified for mutational analyses. My local Cycler Thermal (ICCC) was used for the amplification of exon. Each cycle reaction was set in a final volume of 50 $\mu \mathrm{l}$, which contained 1X buffer (gene net), 1.5-2 $\mathrm{mM} \mathrm{MgCl}_{2}, 200 \mu \mathrm{M}$ dNTPs, 2.4 pmol of each forward and reverse primer and 0.5 units of Taq DNA polymerase (GENE NET). Initial denaturation of DNA was done at $94^{\circ} \mathrm{C}$ for 4 minutes followed by 36 cycles of 45 seconds of denaturation, annealing at $55^{\circ} \mathrm{C}$ for Exon 3 for 35 seconds and extension at $72^{\circ} \mathrm{C}$ for 55 seconds. After 36 cycles, final extension at $72^{\circ} \mathrm{C}$ for 10 Minutes was performed. 
Table 2. Primers of MYOC gene Exons

\begin{tabular}{||cccc||}
\hline Primer name & Primer sequence & Tm & Product size \\
\hline \hline MYOCEX3F & Forward & $59.0 \mathrm{C}$ & $903 \mathrm{bp}$ \\
MYOCEX3F & $\begin{array}{c}\text { Reverse } \\
\text { GAGCCCTGAGCATCTCCTT }\end{array}$ & $59.5 \mathrm{C}$ & $903 \mathrm{bp}$ \\
\hline
\end{tabular}

\subsection{Sequencing}

After purification, samples were sent to first base Malaysia for automated DNA sequencing.

\subsection{Data Analysis}

After the data was obtained, sequencing files were exported to SEQMAN (Lasergene software DNASTAR). For analyzing the trace files normal sequences of respective exons were obtained from UCSC genome browser (http://genome.ucsc.edu/). Trace files were visually examined and any change in the DNA sequence of both sense and anti-sense strands was noted. Files were inspected for any change in the DNA sequences of exons Mutations were first checked in the SNP database (http:/ / www.ncbi.nlm.nih.gov/projects/SNP/) to determine if they were known polymorphisms.

\section{Results}

\subsection{Screening of myocilin gene}

For this study sixty eight of POAG affected individuals were enrolled from different hospital of the Lahore. Individuals were enrolled from different area of the Punjab, Pakistan. They showed both dominant and recessive inheritance of diseases. Linkage study was performed on recessively inherited POAG Glaucoma patients with two microsatellites markers (D1S2815and D1S2851), located upstream and downstream the MYOC gene. Seven out of Fifty two samples were suggestive of linkage to GLC1A locus harbouring the MYOC gene, and five out of fifty two were heterozygous. To check the role of the MYOC gene in these affected individuals, sequencing was performed for coding exon 2 and 3.

\subsection{RMM1}

RMM1 (patient: II:5) was enrolled from Mayo hospital Lahore after complete clinical diagnosis. Patient belongs to District Gujranwala of Punjab. He was 60 years old. He was diagnosed POAG four months ago at the time of sampling. His parents were cousins. There were two affected individuals (II:2 and II:5) in this family. Blood samples of (II:5) was collected from Mayo hospital after complete clinical diagnosis. The symptoms of Glaucoma were detected in the affected person. IOP of his left eye was $24 \mathrm{mmHg}$ while right have $22 \mathrm{mmHg}$. His Corneal thickness was $10.7 \mathrm{~mm}$. This patient had impaired vision and opacification of cornea. After his gonioscopy it was confirmed that he had adult onset Open Angle Glaucoma.

\section{Genotyping and mutational analysis}

This sample was homozygous for marker D1S2851 and D1S2815. Sequencing of exon 2 revealed intronic exonic variants IVS2+35G $>$ A. There was no change observed in exon 3 of Myocilin gene.

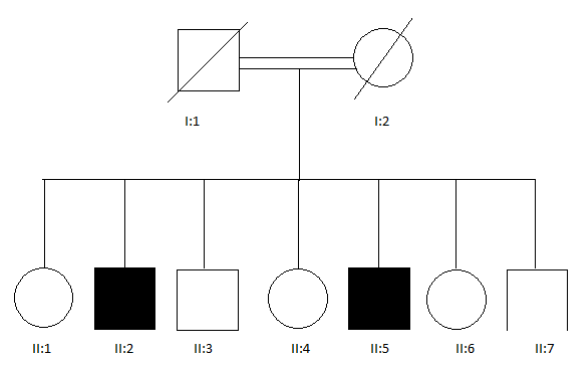

Figure 4. The pedigree of RMM1 sample. 


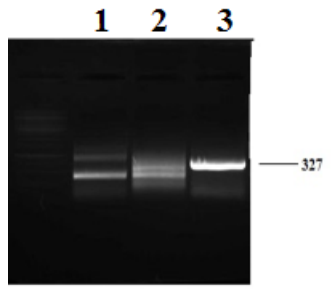

(a)

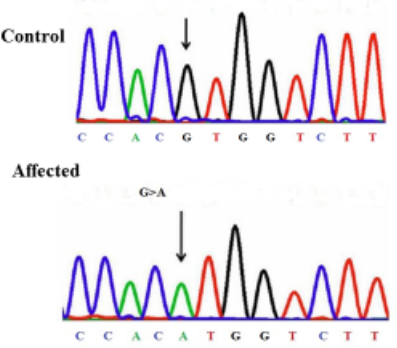

(b)

Figure 5. a) PCR amplified product resolved on $1.5 \%$ agarose gel. Lane 1,2 and 3 showing the amplification of exon 2 of MYOC gene in affected individual (II:5). L denoting the DNA ladder mix.(b) IV2+35G>A nucleotide change indicated by arrow in intronic region of Myoc 2.

\subsection{RM16}

RM16 was recruited from Datta Darbar hospital Lahore. She belonged to District Lahore, Punjab. She was 70 years old. She was diagnosed POAG at the age of 64 (6 year ago). Her parents were cousins.

\section{Clinical diagnosis}

IOP of her left eye was $17 \mathrm{mmHg}$ while right eye have $24 \mathrm{mmHg}$. Her C/D ratio was not mentioned in her medical reports. One of Her elder sister was also Glaucoma patient. She lost vision in her left eye due to unawareness and lack of proper medical treatment. For control of IOP she has undergone trabeculectomy surgery and was on follow up with anti-Glaucoma medication to prevent Glaucoma progression.

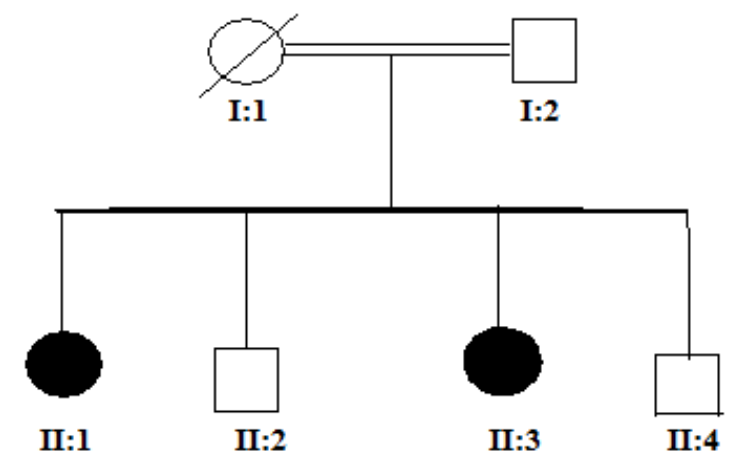

Figure 6. The pedigree of RM16 sample.

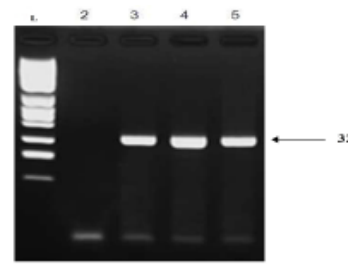

(a)

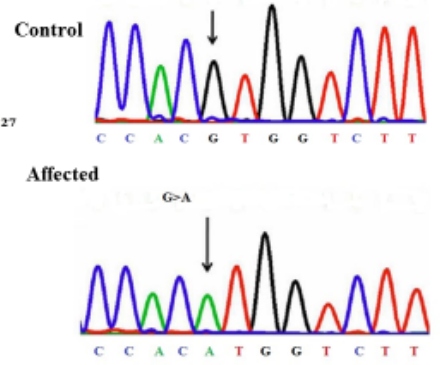

(b)

Figure 7. a) PCR amplified product resolved on $1.5 \%$ agarose gel. Lane 3,4 and 5 showing the amplification of exon 2 of MYOC gene in affected individual (II:3). L denoting the DNA ladder mix . (b) IV2+35G>A nucleotide change indicated by arrow in intronic region of Myoc 2. 


\subsection{RM27}

This patient was enrolled from Data Darbar hospital Lahore. Patient belongs to District Gujranwala of Punjab. The patient was 58 years old. None of his relative was affected from POAG. The patient has high blood pressure problem. The symptoms of primary open angle Glaucoma were noticed in individual at the age of 47. Affected individual have impaired vision and severe opacification of cornea. Patient had megalo-cornea, excessive tearing and loss of vision in both eyes. The patient has IOP of $20 \mathrm{mmHg}$ in her left eye and $22 \mathrm{mmHg}$ in her right eye. Vision field test revealed 6/9 and 6/9. Cup to disc ratio was $0.7 \mathrm{~mm}$ and $0.9 \mathrm{~mm}$ in his both eyes respectively. For control of IOP individual has undergone trabeculectomy surgery and was on follow up with anti-Glaucoma medication to prevent Glaucoma progression.

\section{Genotyping and mutational analysis}

Sequencing results of the coding exon 3 of MYOC gene revealed there is a single Polymorphism Tyr347Tyr, resulting from a T?C transition at nucleotide position 1041, in his genome. But on Sequencing of the coding exon 2 of MYOC gene a sequence variant in intronic region IVS2+35G $>$ A was also identified.

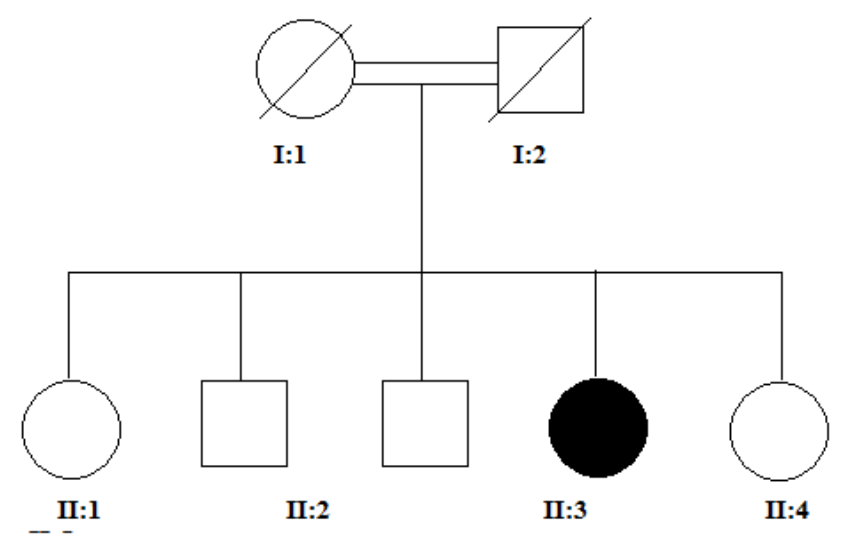

Figure 8. The pedigree of RM27 sample.

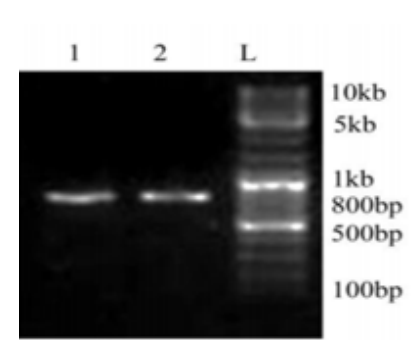

(a)

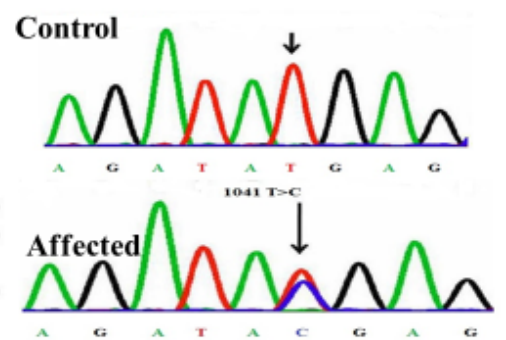

(b)

Figure 9. (a) PCR amplified product resolved on 1.5\% agarose gel. Lane 3 showing the amplification of exon 2 of MYOC gene in affected individuals. L denoting the DNA ladder mix. (b) Sequence derived from Adult POAG patient RM26 shows homozygous IVS2+35G>A Nucleotide change

\subsection{RM26}

This patient (II:4) was belonged from Shahdra Colony Lahore and she came to Datta Darbar Hospital few months before with severe pain in her both eyes. She was the only affected person in her family with consanguineous loop. Parents were normal. Her parents spend their lives with normal eye sight till death. The symptoms of primary open angle Glaucoma were noticed in her at the age of 80 . She had impaired vision. She was also suffering from corneal edema, excessive watering and photophobia and pian due to high IOP. Detailed clinical data was not available for affected individual, because the family was not willing for her 
clinical assessment. Individual had bilateral Glaucoma. Preoperative IOP was $23 \mathrm{mmHg}$ for right eye and $24 \mathrm{mmHg}$ for left eye with a corneal diameter of $11.75 \mathrm{~mm}$ in both eyes. Fundus examination under sedation revealed high Glaucomatous optic cupping with C/D ratio of $0.9 \mathrm{~mm}$ in both eyes. This patient was undergone cyclocropexy for both eyes now she was on medication Blotimfor the control of IOP and now on follow up.

\section{Mutational analysis}

On Sequencing of the coding exon 2 of MYOC gene a sequence variant in intronic region IVS2+35G $>A$ was identified.

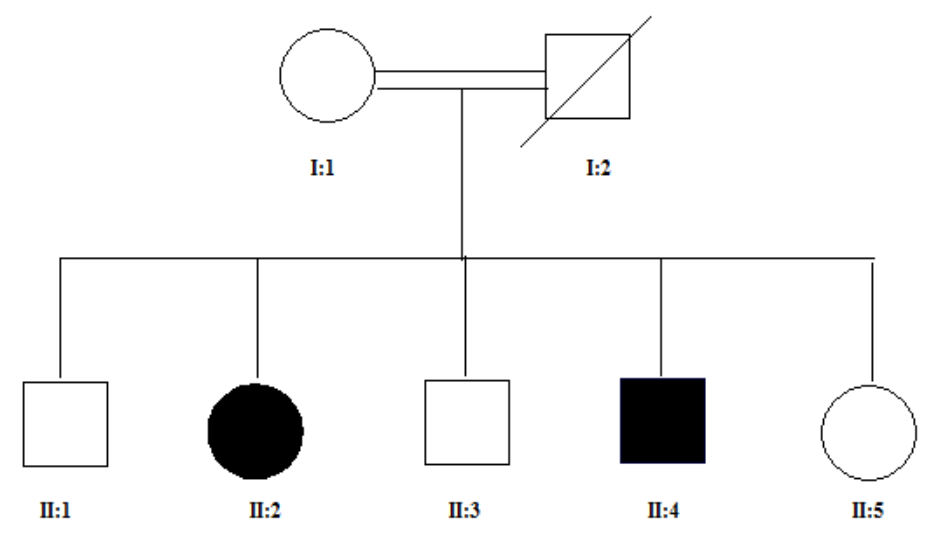

Figure 10. Some representative sporadic samples of POAG genotyped on 6 Poly Acrylamide Gel.

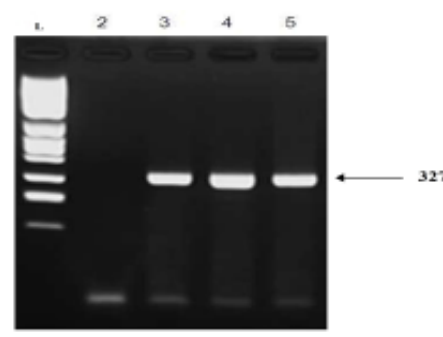

(a)

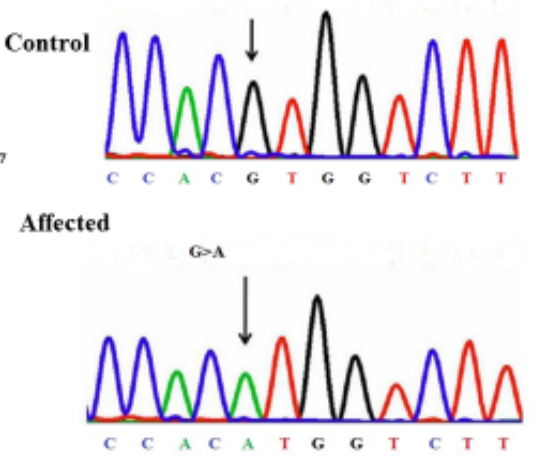

(b)

Figure 11. some representative sporadic sample of POAG genotyped by capillary electrophoresis

\subsection{RM22}

This 65 years old patient (II:4) belongs to district Sheikhopora, Punjab. He was enrolled from Mayo Hospital Lahore. He was diagnosed as POAG patient before 15 years, since he was on IOP control medication so can minimize the progression of disease. His parents were cousins, none of other family member affected with Glaucoma. He was blind from his left eye. Both eyes had very high IOP $65 \mathrm{mmHg}$ in left and $66 \mathrm{mmHg}$ in right eye. Fundus examination under sedation revealed high Glaucomatous optic cupping with C/D ratio of $0.9 \mathrm{~mm}$ in right and $1.0 \mathrm{~mm}$ in left eye.

\section{Mutational analysis}

No mutation was identified in exon 3 of MYOC, but a variant IVS2+35G>A was observed in sample of patient (II:3). 


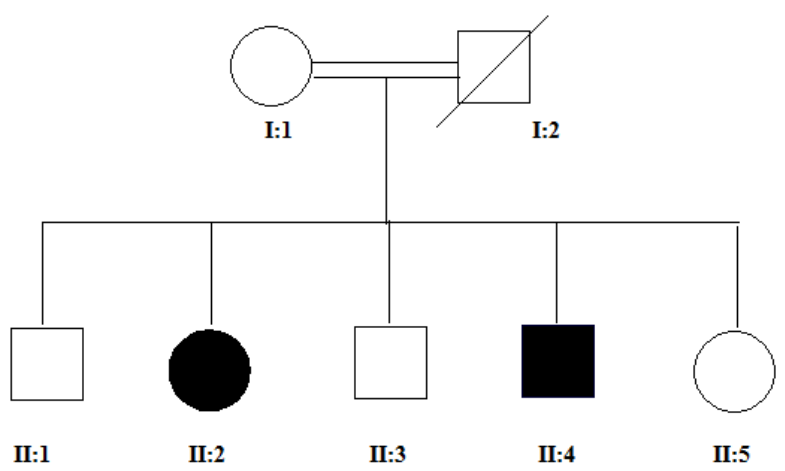

Figure 12. The pedigree of RM27 sample.

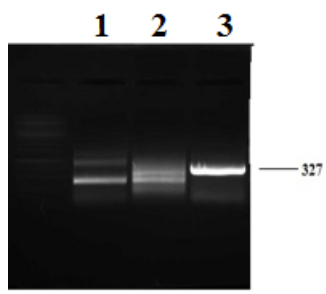

(a)

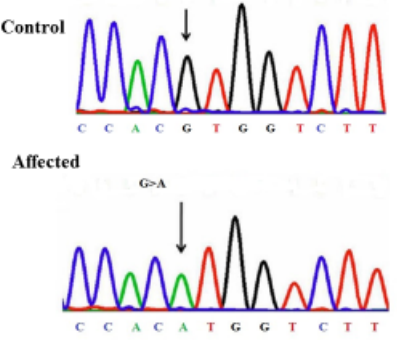

(b)

Figure 13. a) PCR amplified product resolved on 1.5\% agarose gel. Lane 3 showing the amplification of exon 2 of MYOC gene in affected individuals. L denoting the DNA ladder mix. (b) Sequence derived from Adult POAG patient RM26 shows homozygous IVS2+35G $>$ A Nucleotide change

\subsection{RMC2}

This patient (II:3) belong to District Lahore, Punjab. He was enrolled from Datta Darbar Hospital Lahore. Patient was 45 years old and diagnosed Glaucoma few years ago. In his family he was the only person affected with Glaucoma with consagenious loop. Severe symptoms of primary open angle Glaucoma were noticed. He had bilateral buphthalmos, corneal edema, epiphora, enlarged globe and photophobia in both eyes. Examination under Anaesthesia (EUA) was done. Premedication Intra Ocular Pressure of Patient was 18 $\mathrm{mmHg}$ in both eyes with a corneal diameter of $12 \mathrm{~mm}$ and $13 \mathrm{~mm}$ for right eye and left eye respectively. This patient was on anti-Glaucoma medication for control of IOP and on life time follow up.

\section{Mutational analysis}

On Sequencing of the coding exon 2 of MYOC gene a sequence variant in intronic region IVS2+35G $>A$ was identified.

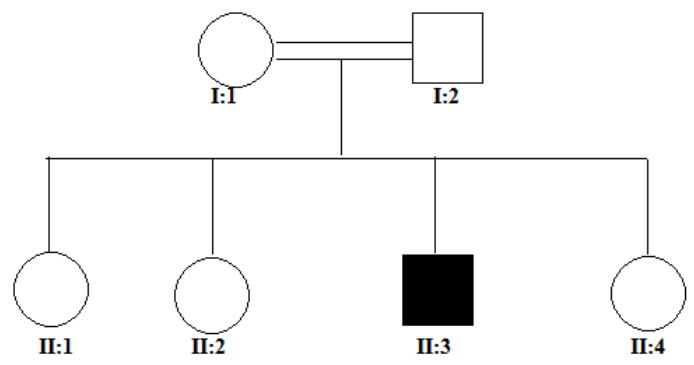

Figure 14. The pedigree of RMC2 sample. 


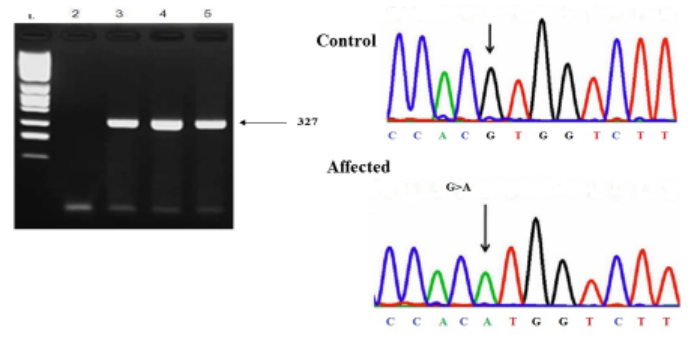

(a)

(b)

Figure 15. (a) PCR amplified product resolved on 1.5\% agarose gel. Lane 4 showing the amplification of exon 2 of MYOC gene in affected individuals. L denoting the DNA ladder mix. (b) Sequence derived from Adult POAG patient RMC2 shows homozygous IVS2+35G>A Nucleotide change

\subsection{RM15}

This patient (II:5) was enrolled from Datta Darbar Hospital Lahore. She belongs to Sabzazar colony District Lahore, Punjab. She was a 62 years male diagnosed as POAG patient just few weeks ago. This family also a consagenious marriages loop. A sister of patient was also had symptoms of Glaucoma. Patient had complaint of asthma from many years. Patient had severe symptoms of Glaucoma with IOP $26 \mathrm{mmHg}$ and $31 \mathrm{mmHg}$ in her left and right eye respectively. After her fundus examination cup to dics ratio was revealed $0.3 \mathrm{~mm}$ in his both eyes. His vision field test also showed impairment in his both eyes. Patient was on anti-glaucomic medication betagan and cordazal for life time to control IOP.

\section{Mutational analysis}

On Sequencing of the coding exon 2 of MYOC gene a sequence variant in intronic region IVS2+35G $>A$ was identified.

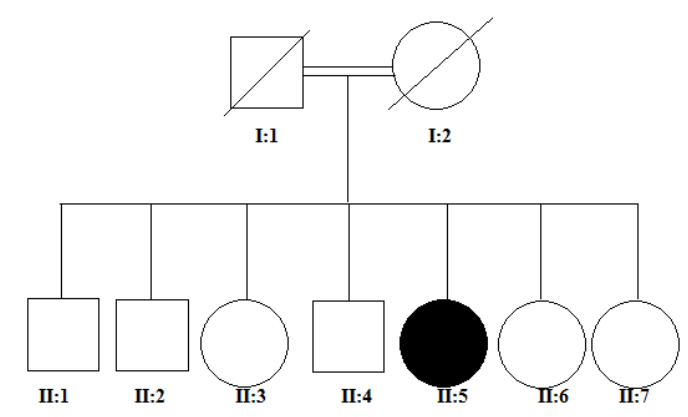

Figure 16. The pedigree of RM15 sample.
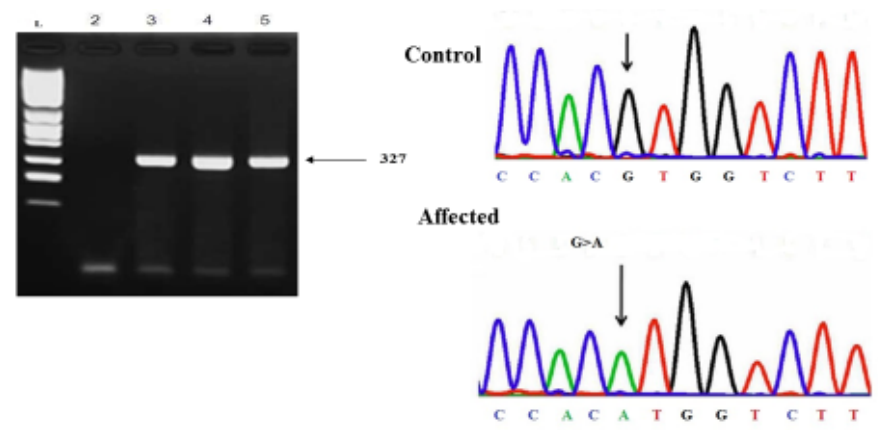

(a)

(b)

Figure 17. (a) PCR amplified product resolved on 1.5\% agarose gel. Lane 6 showing the amplification of exon 2 of MYOC gene in affected individuals. L denoting the DNA ladder mix. (b) Sequence derived from Adult POAG patient RM15 shows homozygous IVS2+35G $>$ A Nucleotide change 
Table 3. Primers of MYOC gene Exons

\begin{tabular}{|c|c|c|c|c|c|c|c|}
\hline $\begin{array}{l}\text { Patient } \\
\text { identity }\end{array}$ & Sex & Age & Clinical features & $\begin{array}{l}\mathrm{C} / \mathrm{D} \text { ratio } \\
\text { Right eye }\end{array}$ & $\begin{array}{l}\text { C/D ratio } \\
\text { Left eye }\end{array}$ & $\begin{array}{c}\text { IOP } \\
\text { mmHg } \\
\text { Right eye }\end{array}$ & $\begin{array}{l}\text { IOP } \\
\text { mmHg } \\
\text { Left eye }\end{array}$ \\
\hline RMM & M & 60 & $\begin{array}{l}\text { Corneal edema } \\
\text { right eye }\end{array}$ & 10.7 & ND & 24 & 22 \\
\hline RM16 & $\mathrm{F}$ & 64 & $\begin{array}{l}\text { Vision lost in } \\
\text { her left eye }\end{array}$ & ND & ND & 24 & 17 \\
\hline RM26 & $\mathrm{F}$ & 80 & $\begin{array}{l}\text { Corneal edema, } \\
\text { excessive watering } \\
\text { photophobia pain } \\
\text { Impaired vision }\end{array}$ & 0.9 & 0.9 & 23 & 24 \\
\hline RM27 & M & 58 & $\begin{array}{l}\text { Opacification of cornea } \\
\text { megalocornea }\end{array}$ & 0.7 & 0.9 & 22 & 20 \\
\hline RM15 & $\mathrm{M}$ & 62 & $\begin{array}{l}\text { Impairment of vision } \\
\text { in both eyes }\end{array}$ & 0.3 & 0.3 & 31 & 26 \\
\hline $\mathrm{RMC}$ & $\mathrm{F}$ & 45 & $\begin{array}{l}\text { Bilateral buphthalmos, } \\
\text { Corneal edema, Epiphora, } \\
\text { enlarged globe photophobia }\end{array}$ & ND & ND & 18 & 18 \\
\hline RM22 & M & 50 & $\begin{array}{l}\text { Blind from right eye } \\
\text { impaired vision in left }\end{array}$ & 0.9 & 1.0 & 65 & 66 \\
\hline
\end{tabular}

Table 4. : List of SNPs and Variant identified in Exon 3 and exon 2 of MYOC gene

\begin{tabular}{||cccc||}
\hline Patient identity & Exon & Position & SNP/Variation \\
\hline \hline RM26 & 3 & c.1041 T $\rightarrow \mathrm{C}$ & Tyr 347 tyr \\
RM27 & 3 & Insertion of T at 755 & Not known \\
All the samples & Intronic region of exon 2 & IVS2+35 G $>\mathrm{A}$ & Variant \\
\hline
\end{tabular}

\section{Discussion}

The aim of this study was to initiate genetic study on recessively inherited late onset Glaucoma in Pakistani population. Adult onset open angle Glaucoma (AOAG) genetics is complex and there are many factors which are involved for disease pathogenesis. Myocilin is causative gene for POAG Glaucoma in many population of the world. For this study 52 patients were enrolled in which 45 were from cousin parents while in remaining cases POAG was dominantly inherited. Patients having recessively inherited with late onset Glaucoma were genotyped with two fluorescently labelled microsatellite markers D1S2815 and D1S2851. Results showed 7 out of 52 were homozygous for both markers of Myocilin gene. Therefore 7 and remaining 5 samples were sequenced for Myocilin coding exon 2 and 3. Sequencing result showed one polymorphism in exon 3 and one known variants in intronic exonic boundary of exon 2.

Author Contributions: All authors contributed equally to the writing of this paper. All authors read and approved the final manuscript.

Conflicts of Interest: "The authors declare no conflict of interest."

\section{References}

[1] Sarfarazi, M. (1997). Recent advances in molecular genetics of Glaucomas. Human molecular genetics, 6(10), 1667-1677.

[2] Chitsazian, F., Tusi, B. K., Elahi, E., Saroei, H. A., Sanati, M. H., Yazdani, S., \& Zareei, R. (2007). CYP1B1 mutation profile of Iranian primary congenital Glaucoma patients and associated haplotypes. The Journal of Molecular Diagnostics, 9(3), 382-393.

[3] Fuse, N. (2010). Genetic bases for Glaucoma. The Tohoku journal of experimental medicine, 221(1), 1-10.

[4] Ritu \& Garg, M. (2014). A review on fingerprint-based identification system. International Journal of Advanced Research in Computer and Communication Engineering, 3(3), March 2014.

[5] Iqbal, S., Khan, Z., Shah, S. A., \& Khan, M. Y. (2011). Types and presentation of Glaucoma. Journal of Postgraduate Medical Institute (Peshawar-Pakistan), 22(4), 324-332. 
[6] Pechuho, M. A., Jxsiddiqui, S. A., Nangrejo, K. M., Sahto, A. A., Ali Shah, S. I., \& Qadir, A. (2011). Audit of the Glaucoma clinic. Medical Channel, 17(3), 25-28.

[7] Firasat, S., Riazuddin, S. A., Hejtmancik, J. F., \& Riazuddin, S. (2008). Primary congenital Glaucoma localizes to chromosome 14q24. 2-24.3 in two consanguineous Pakistani families. Molecular vision, 14, 1659-1665.

[8] Gemenetzi, M., Yang, Y., \& Lotery, A. J. (2012). Current concepts on primary open-angle Glaucoma genetics: a contribution to disease pathophysiology and future treatment. Eye, 26(3), 355-369.

[9] Alward, W. L., Fingert, J. H., Coote, M. A., Johnson, A. T., Lerner, S. F., Junqua, D. \& Stone, E. M. (1998). Clinical features associated with mutations in the chromosome 1 open-angle Glaucoma gene (GLC1A). New England Journal of Medicine, 338(15), 1022-1027.

[10] Rose, R., Karthikeyan, M., Anandan, B., \& Jayaraman, G. (2007). Myocilin mutations among primary open angle Glaucoma patients of Kanyakumari district, South India. Molecular vision, 13, 497-503.

[11] Willoughby, C. E., Ponzin, D., Ferrari, S., Lobo, A., Landau, K., \& Omidi, Y. (2010). Anatomy and physiology of the human eye: effects of mucopolysaccharidoses disease on structure and functionÚa review. Clinical E Experimental Ophthalmology, 38, 2-11.

[12] Khan, M. I., Micheal, S., Akhtar, F., Ahmed, W., Ijaz, B., Ahmed, A., \& Qamar, R. (2010). The association of glutathione S-transferase GSTT1 and GSTM1 gene polymorphism with pseudoexfoliative Glaucoma in a Pakistani population. Molecular vision, 16, 2146-2152.

[13] Waryah, A. M., Narsani, A. K., Sheikh, S. A., Shaikh, H., \& Shahani, M. Y. (2013). The novel heterozygous Thr377Arg MYOC mutation causes severe Juvenile Open Angle Glaucoma in a large Pakistani family. Gene, 528(2), 356-359.

[14] Vincent, A. L., Billingsley, G., Buys, Y., Levin, A. V., Priston, M., Trope, G.,\& Héon, E. (2002). Digenic inheritance of early-onset Glaucoma: CYP1B1, a potential modifier gene. The American Journal of Human Genetics, 70(2), 448-460. 